\title{
La organización del mercado del suelo y los subsidios a la localización de vivienda como soluciones desde la política neoliberal en Chile y México
}

\author{
A organização do mercado de terras e subsídios para a \\ localização da habitação como soluções na política \\ neoliberal no Chile e no México \\ Organization of land market and location subsidies of \\ housing as solutions in neoliberal politics in Chile and Mexico
}

\author{
Rodrigo Hidalgo Dattwyler [a] [D, Marco Calleja Martínez [a] [D], \\ Voltaire Alvarado Peterson [b] [D, Luis Salinas Arreortua [c] (DD)
}

[a] Pontificia Universidad Católica de Chile (PUC-Chile), Instituto de Geografía, Santiago, Chile

[b] Universidad de Concepción (UdeC-Chile), Departamento de Geografía, Concepción, Chile

[c] Universidad Nacional Autónoma de México (UNAM-México), Instituto de Geografía, Ciudad de México, México

Cómo citar: Dattwyler, R. H., Martínez, M. C., Peterson, V. A. \& Arreourtua, L. S. (2021). La organización del mercado del suelo y los subsidios a la localización de vivienda como soluciones desde la política neoliberal en Chile y México. urbe. Revista Brasileira de Gestão Urbana, v. 13, e20190170. DOI https://doi.org/10.1590/2175-

3369.013.e20190170

\section{Resumen 1}

\begin{abstract}
Esta investigación se plantea la necesidad de identificar el origen del modelo de subsidios a la vivienda social, orientados a la localización y contención urbana en Chile y México, analizando, desde una perspectiva crítica, los procesos de estructuración del marco normativo y de las políticas públicas de corte neoliberal, con la construcción del modelo de gestión territorial para el desarrollo. Para ello se plantea si es posible considerar a la política subsidiaria de vivienda social actual, como un modelo emulado por gobiernos latinoamericanos para materializar la desregulación del mercado del suelo urbano en la región. Específicamente analizan los marcos normativos e institucionales de la política habitacional chilena, con la implementación del sistema condicional de subsidios a la localización en México.
\end{abstract}

Palabras clave: Subsidio. Vivienda social. Chile. México.

\footnotetext{
1 Esta investigación se enmarca en el proyecto FONDECYT Regular 1191555 "La producción de vivienda subsidiada en ciudades fluviales, marinas y lacustres en Chile: integración y sostenibilidad 2000 - 2017”.
}

RHD es geógrafo, doctor en Geografía, e-mail: rhidalgd@uc.cl

MCM es abogado, candidato a doctor en Geografía, e-mail: macalleja@uc.cl

VAP es profesor, doctor en Geografía, e-mail: voalvarado@udec.cl

LSA es geógrafo, doctor en Geografía, e-mail: lsalinas@igg.unam.mx 


\section{Resumo}

Esta pesquisa levanta a necessidade de identificar a origem do modelo de subsídios à habitação social, visando a localização e a contenção urbana no Chile e no México, analisando, sob uma perspectiva crítica, os processos de estruturação do marco regulatório e das políticas públicas. neoliberal, com a construção do modelo de gestão territorial para o desenvolvimento. Para isso, questiona-se se é possível considerar a atual política subsidiária de habitação social, como um modelo emulado pelos governos latino-americanos para materializar a desregulamentação do mercado de terras urbanas na região. Especificamente, eles analisam as estruturas regulatórias e institucionais da política habitacional chilena, com a implementação do sistema condicional de subsídios por localização no México.

Palavras-chave: Subsídio. Habitação social. Chile. México.

\section{Abstract}

This research is based on the need to identify the origin of the social housing subsidy model, oriented to location and urban containment in Chile and Mexico, analyzing, from a critical perspective, the structuring processes of neoliberal law and public policies, with the construction of the territorial management model for development. To do this, it is asked whether it is possible to consider the current subsidiary social housing policy, as a model emulated by Latin American governments to materialize the deregulation of the urban land market in the region. Specifically, they analyze the regulatory and institutional frameworks of Chilean housing policy, with the implementation of the conditional system of location subsidies in Mexico.

Keywords: Subsidy. Social housing. Chile. Mexico.

\section{Introducción}

Con profundos cambios en el régimen de acumulación y regulación, decantados en la conformación de un nuevo paradigma de desarrollo regional, los sistemas políticos y económicos latinoamericanos promovieron modelos orientados a una nueva geografía económica (Moncayo, 2002). Ejercicios respecto al crecimiento endógeno, acumulación flexible de capital y competitividad territorial adquirieron intensidades diferenciadas en cada país, debido a factores endógenos particulares y complejos. Estas nuevas reglas sobre el régimen de acumulación en el caso de Chile, por ejemplo, se traducen alternativas regulatorias desarticuladoras del bienestar en tanto al Estado (De Mattos, 1999). Esta transición, originada hacia finales de la década de 1970, desarma la orientación económica de pleno empleo y mercados cerrados, orientándose a la masificación del consumo desde otros paradigmas (Jessop, 1999).

Ante este escenario emerge un modelo Shumpeteriano de Estado de Trabajo, con nuevas exigencias y factores donde el Estado cede posiciones frente a los gobernados, siendo estas cesiones asumidas por empresas privadas. La flexibilización del mercado, la innovación en los procesos productivos, la emergencia de consorcios público-privados para generar soluciones, tradicionalmente atendidas solo por el Estado, ingresan a indicadores inéditos de competitividad. En los casos a presentar de Chile y México, estas transformaciones de traducen en drásticas modificaciones sobre la producción inmobiliaria y su financiarización (Cattaneo, 2011; Girón \& Chapoy, 2009). Nuevas legislaciones, más flexibles, introdujeron cambios significativos en la estructura de propiedad del suelo y la participación protagónica de nuevos actores privados, al amparo de instituciones públicas nacionales y organismos internacionales en el control de mercados financieros para financiar el desarrollo (Girón \& Chapoy, 2009).

Para finales del siglo XX, el modelo económico neoliberal permeó en América Latina sobre todos los puntos de contacto entre el Estado y su población. Las políticas de vivienda no fueron excepción, expresándose una serie de efectos socio-espaciales (Imilan et al.,2016). El primero de ellos es la propietarización de la vivienda, que reemplaza regímenes alternativos de propiedad comunal, colectiva o 
cooperativa, imponiéndose un esquema privado de mercado formal, vinculado a la clase media. El segundo de los efectos se caracteriza por dinámicas centrífugas de expulsión de las clases trabajadoras hacia nuevas periferias urbanas, fenómeno arraigado profundamente en el caso chileno. Para el caso mexicano, este segundo elemento constituye un negocio rentable para determinadas empresas inmobiliarias, mediante el traspaso de fondos públicos y el fortalecimiento del sistema de crédito hipotecario por Organismos Nacionales de Vivienda, en ausencia de inversión en infraestructura y equipamiento urbano. Esto último distinguiendo los procesos de focalización en el acceso a soluciones habitacionales, alejándose de la informalidad para situarse sobre las clases trabajadoras (Imilan et al., 2016).

El sistema neoliberal modificó la perspectiva sobre el problema de vivienda en la región, tradicionalmente percibido como carga del Estado por ser un bien necesario y sólido mecanismo para contener la reproducción de informalidades urbanas. La vivienda se transformó en una oportunidad para la movilización de la economía, la sistematización de la política subsidiaria y la conformación de capital político. Con la promulgación de la Ley General de Asentamientos Humanos en 1976 (DOF, 1976), en México se inauguraba este cambio, aunque con la nacionalización de la banca en 1989, comienza el apogeo de las empresas desarrolladoras de vivienda, permitiéndole a un sector importante de la población acceder al crédito hipotecario.

Las políticas de vivienda en México han sido ampliamente analizadas en México (Higuera \& Rubio, 2011; Isunza, 2010; Puebla, 2006; Salinas, 2016; Schteingart \& García, 2006; Schteingart \& Patiño, 2006) y Chile (Castillo-Fernández, 2018; Hidalgo et al., 2017; Naranjo \& Purcell, 2010; Ossul-Vermehren, 2018; Rodríguez \& Sugranyes, 2004; Urrutia, 2018; Yopo Díaz et al., 2012). En este sentido, a pesar de lo que plantea Rolnik sobre la aplicación del modelo chileno en diversos países en América Latina, pocos trabajos abordan su implementación política-normativa (Rolnik, 2012). Lentini, por ejemplo, analiza la política habitacional en Chile y Argentina en la década de los noventa, de manera particular, el rol del Estado y la reproducción del enfoque facilitador (Lentini, 2005).

Por su parte, Rojas et al. (2013) comparan los modelos de financiación de vivienda entre México, Chile y Colombia. Un trabajo más reciente (Imilan et al., 2016), además de analizar los efectos socio-espaciales en Santiago de Chile, Ciudad de México y Londres, discute la crisis de la vivienda social. Sin embargo, a pesar de que mucho se ha escrito sobre la política de vivienda en Chile, resulta sorprendente que la reproducción del modelo en México a fines del siglo XX, y de manera particular con los gobiernos de alternancia (20002012), se haya adoptado a sabiendas de las consecuencias inicialmente descritas.

Resulta evidente que el éxito del modelo de política de vivienda reproducido en distintos países latinoamericanos está en función de la reproducción del capital y no en sus resultados sociales. Como ocurrió con el modelo de privatización de los Fondos de Pensiones. Rolnik plantea la influencia del modelo de vivienda chileno sobre otros países de la región:

Se ha encomiado al modelo chileno como una de las mejores prácticas por su transparencia, por la escala del traspaso del suministro de viviendas a proveedores del sector privado (considerados más eficientes y eficaces que el gobierno para abordar la diversidad de la demanda de vivienda) y por dirigirse a los pobres. El modelo se ha duplicado ampliamente en América Latina (Brasil, Colombia, Costa Rica, Ecuador, El Salvador, Guatemala, México, Panamá, Perú y Venezuela (Rolnik, 2012, p. 14$15)$.

Desde esta perspectiva, el manuscrito propone una revisión sobre la evolución de los procesos de subsidiarización económica detonantes de un modelo permanentemente examinado, como el chileno, pero carente de experiencias comparativas de matriz política y racionalidad económica. Ciertamente, el denominado modelo chileno establece patrones de integración entre el Estado y agentes privados, siendo cuestionable el sentido reproductivo de la propiedad habitacional como generadora de ciudad. Pero ¿cuáles son sus límites?, ¿por qué es comparable con la experiencia de México?, ¿qué tipo de urbanización establece este modelo de provisión de viviendas? Entendiendo que ni la gentrificación ni la segregación pueden 
explicar la totalidad de las contradicciones del desarrollo de un espacio neoliberal, estas cuestiones podrían aportar a una discusión conceptual y teórica respecto a los resultados espaciales de estas políticas en ambos países.

\section{La evolución de las políticas de fomento a la vivienda social en Chile y México}

El texto constitucional mexicano de 1917 contiene el primer antecedente de derecho a la vivienda en el mundo, al reconocer en su artículo 123 la obligación de los patrones de toda negociación agrícola, industrial, minera o cualquiera otra, para proporcionar a sus trabajadores -habitaciones cómodas e higiénicas-, limitando el monto del valor del arriendo a pagar por éstos (EUM, 1917). Sin embargo, no es sino hasta 1983 que una reforma constitucional reconoce expresamente el derecho a la vivienda en México, agregando que esta deberá ser digna y decorosa. En este sentido, el caso chileno es divergente, al no considerar en su orden jurídico un reconocimiento expreso del derecho a la vivienda. A pesar de ello, desde la óptica del Derecho Internacional, este reconocimiento es indirecto, conseguido con la adhesión del Estado chileno en 1971 al Pacto Internacional de Derechos Económicos, Sociales y Culturales (Naciones Unidas, 1976), el cual reconoce el derecho a la vivienda adecuada (Ver tabla 1).

Como un esfuerzo para brindar soluciones prácticas al problema de los asentamientos precarios en los albores del siglo XX, la influencia del higienismo europeo se hizo sentir en Latinoamérica. En ambos países emergen legislaciones que intentan palear las condiciones insalubres de la vivienda de los más pobres, siendo menos sustancial en el caso de México, con ocasión de la revolución.

Otra coincidencia temporal relevante está en el fomento a la vivienda en alquiler, que surge como paliativo a los movimientos obreros que tuvieron auge en la década de 1920, no solo en las naciones estudiadas, sino en otras latitudes de la región y el mundo. En esos años se consolidó un sólido modelo donde las instituciones públicas jugaron un rol protagónico en el fomento a la habitación popular, asumiendo las entidades gubernamentales un papel activo para aumentar el parque de vivienda, desplazando a otras instituciones como la iglesia católica en el caso de Chile. En este período hay una promoción directa del Estado, mediante un modelo de nacional-desarrollista que procura la institucionalización de la financiación a través de organismos públicos y se expresa en la fundación de la Caja de Habitación Popular en Chile y el Banco Nacional Hipotecario Urbano y de Obras Públicas en la nación norteamericana.

La segunda mitad del siglo XX avizoraría grandes cambios para los dos países latinoamericanos, al tiempo experimentar una demandad de vivienda que toma nuevas proporciones, para lo cual Chile consolida el fomento a la vivienda a través de la creación de la Corporación de Vivienda (CORVI) en 1953 y México responde en primer lugar ofreciendo soluciones habitacionales para su naciente burocracia. En la década de 1970, se crea el Instituto del Fondo Nacional de Vivienda para los Trabajadores (INFONAVIT), el Fondo de la Vivienda del Instituto de Seguridad y Servicios Sociales de los Trabajadores del Estado (FOVISSSTE), así como el Fondo de Operación y Descuento Bancario a la Vivienda (FOVI), que consolidó el modelo desarrollista con la promulgación de la Ley General de Asentamientos Humanos en 1976 (DOF, 1976) y la sucesiva creación del Fideicomisos públicos para la promoción de la habitación popular durante el siguiente decenio.

Por su parte, en Chile se instituyó en 1979 la Política Nacional de Desarrollo Urbano que, bajo dictadura militar, fue considerada como la primera etapa de reformas neoliberales, que se complementaron en 1983 con una serie de iniciativas que consolidarían un modelo centrado en la privatización de la provisión de servicios básicos, incluidos el fomento a la vivienda, que a la par acrecentó los movimientos urbanopopulares (MINVU, 2014). La cesión del control sobre la provisión de vivienda social en México adquirió formas distintas dado el contexto político disímil, ahí la cesión ocurrió durante la década de 1990 a través de reformas a su constitución y a las leyes del INFONAVIT (GF-CDEMX, 1972) y el reglamento del FOVISSSTE 
(GF-CDEMX, 2015b), que terminaron cediendo a un puñado de grandes inmobiliarias, el control casi absoluto de la producción, fomento, financiamiento y estrategia de vivienda social (Ver tabla 2).

Por último, la política subsidiaria fue perfeccionándose durante los primeros años del siglo XXI por ambos países para la dotación de apoyos gubernamentales condicionados por la localización de la solución habitacional. En México inicia con los llamados subsidios al frente en 2007, a través del Programa de Esquemas de Financiamiento y Subsidio Federal para Vivienda. La política chilena de subsidio a la localización de vivienda inicia en cambio en 2006, con el Programa Fondo Solidario de Vivienda (Ver tabla 1).

Tabla 1 - Iniciativas estatales de políticas de vivienda comparables entre México y Chile

\begin{tabular}{|c|c|c|c|c|c|c|}
\hline \multirow[b]{2}{*}{ Característica } & \multicolumn{3}{|l|}{ México } & \multicolumn{3}{|l|}{ Chile } \\
\hline & $\begin{array}{l}\text { Iniciativa / } \\
\text { medida }\end{array}$ & $\begin{array}{l}\text { Instrumento } \\
\text { Legal }\end{array}$ & $\begin{array}{l}\text { Año de } \\
\text { implementación }\end{array}$ & $\begin{array}{l}\text { Iniciativa / } \\
\text { medida }\end{array}$ & $\begin{array}{l}\text { Instrumento } \\
\text { legal }\end{array}$ & $\begin{array}{l}\text { Año de } \\
\text { implementación }\end{array}$ \\
\hline \multirow[t]{2}{*}{$\begin{array}{l}\text { Promoción de } \\
\text { Vivienda } \\
\text { higiénica }\end{array}$} & $\begin{array}{l}\text { Promoción de } \\
\text { la Vivienda } \\
\text { higiénica }\end{array}$ & $\begin{array}{l}\text { Ley sobre } \\
\text { Casas de } \\
\text { Obreros y } \\
\text { Empleados } \\
\text { Públicos } \\
\text { (Aplicación } \\
\text { local) }\end{array}$ & 1906 & $\begin{array}{l}\text { Promoción de } \\
\text { la Vivienda } \\
\text { higiénica }\end{array}$ & $\begin{array}{l}\text { Ley de } \\
\text { habitaciones } \\
\text { obreras }\end{array}$ & 1906 \\
\hline & $\begin{array}{l}\text { Obligación } \\
\text { por los } \\
\text { patrones } \\
\text { para otorgar } \\
\text { vivienda } \\
\text { cómoda e } \\
\text { higiénica a } \\
\text { sus } \\
\text { trabajadores }\end{array}$ & $\begin{array}{l}\text { Constitución } \\
\text { Federal }\end{array}$ & 1917 & & & \\
\hline $\begin{array}{l}\text { Fomento a la } \\
\text { vivienda en } \\
\text { renta }\end{array}$ & $\begin{array}{l}\text { Construcción } \\
\text { de vivienda } \\
\text { de bajo costo } \\
\text { en áreas } \\
\text { centrales } \\
\text { para arriendo } \\
\text { a población } \\
\text { obrera }\end{array}$ & De facto & $1925-1940$ & $\begin{array}{l}\text { Movimientos } \\
\text { de } \\
\text { arrendatarios }\end{array}$ & $\begin{array}{l}\text { Ley de } \\
\text { Habitaciones } \\
\text { Baratas }\end{array}$ & 1925 \\
\hline $\begin{array}{l}\text { Producción de } \\
\text { vivienda } \\
\text { encabezada } \\
\text { por el Estado }\end{array}$ & $\begin{array}{l}\text { Sistema de } \\
\text { promoción } \\
\text { estatal } \\
\text { directa }\end{array}$ & $\begin{array}{l}\text { Artículo } 123 \\
\text { constitucional }\end{array}$ & A partir de 1940 & $\begin{array}{l}\text { Protagonismo } \\
\text { del Estado } \\
\text { como agente } \\
\text { dominante en } \\
\text { modelo del } \\
\text { "nacional } \\
\text { desarrollismo". } \\
\text { Creación de } \\
\text { la Caja de } \\
\text { Habitación } \\
\text { Popular }\end{array}$ & $\begin{array}{l}\text { Leyes de } \\
\text { Fomento de } \\
\text { la Edificación } \\
\text { Obrera, Ley } \\
\text { General de } \\
\text { Urbanismo y } \\
\text { Construcción }\end{array}$ & Década 1930 \\
\hline $\begin{array}{l}\text { Fondo público } \\
\text { para } \\
\text { financiamiento } \\
\text { de vivenda }\end{array}$ & $\begin{array}{l}\text { Producción } \\
\text { de vivienda } \\
\text { para clase } \\
\text { media/baja }\end{array}$ & & A partir de 1949 & $\begin{array}{l}\text { Préstamos } \\
\text { para viviendas } \\
\text { populares }\end{array}$ & $\begin{array}{l}\text { Plan Nacional } \\
\text { de Vivienda }\end{array}$ & Década de 1940 \\
\hline $\begin{array}{l}\text { Movimientos } \\
\text { sociales por la } \\
\text { vivenda }\end{array}$ & $\begin{array}{l}\text { Movimiento } \\
\text { Urbano } \\
\text { Popular }\end{array}$ & De facto & $\begin{array}{l}\text { Décadas 1960- } \\
1980\end{array}$ & $\begin{array}{l}\text { Movimientos } \\
\text { de pobladores }\end{array}$ & De facto & $1956-1990$ \\
\hline
\end{tabular}


La organización del mercado del suelo y los subsidios a la localización de vivienda como soluciones desde la política neoliberal en Chile y México

Tabla 1 - Iniciativas estatales de políticas de vivienda comparables entre México y Chile

(conclusión)

\begin{tabular}{|c|c|c|c|c|c|c|}
\hline \multirow[b]{2}{*}{ Característica } & \multicolumn{3}{|l|}{ México } & \multicolumn{3}{|l|}{ Chile } \\
\hline & $\begin{array}{l}\text { Iniciativa / } \\
\text { medida }\end{array}$ & $\begin{array}{l}\text { Instrumento } \\
\text { Legal }\end{array}$ & $\begin{array}{l}\text { Año de } \\
\text { implementación }\end{array}$ & $\begin{array}{l}\text { Iniciativa / } \\
\text { medida }\end{array}$ & $\begin{array}{l}\text { Instrumento } \\
\text { legal }\end{array}$ & $\begin{array}{l}\text { Año de } \\
\text { implementación }\end{array}$ \\
\hline $\begin{array}{l}\text { Institucionalización } \\
\text { del fomento a la } \\
\text { vivenda }\end{array}$ & $\begin{array}{l}\text { Creación de } \\
\text { INFONAVIT y } \\
\text { FOVISSSTE }\end{array}$ & $\begin{array}{l}\text { Ley de } \\
\text { INFONAVIT y } \\
\text { Ley de los } \\
\text { Trabajadores al } \\
\text { Servicio del } \\
\text { Estado }\end{array}$ & 1972 & $\begin{array}{l}\text { Creación de la } \\
\text { Corporación de } \\
\text { la Vivienda } \\
\text { (CORVI) }\end{array}$ & $\begin{array}{l}\text { Ley de } \\
\text { Construcciones } \\
\text { y urbanización }\end{array}$ & 1953 \\
\hline $\begin{array}{l}\text { Modelo } \\
\text { desarrollista de } \\
\text { vivenda }\end{array}$ & $\begin{array}{l}\text { Promulgación } \\
\text { de Ley General } \\
\text { de } \\
\text { Asentamientos } \\
\text { Humanos }\end{array}$ & $\begin{array}{l}\text { Ley General de } \\
\text { Asentamientos } \\
\text { Humanos }\end{array}$ & 1976 & $\begin{array}{l}\text { Política de } \\
\text { Desarrollo } \\
\text { Urbano }\end{array}$ & $\begin{array}{l}\text { Política } \\
\text { Nacional de } \\
\text { Desarrollo } \\
\text { Urbano }\end{array}$ & 1979 \\
\hline $\begin{array}{l}\text { Repliegue del } \\
\text { Estado en el } \\
\text { Fomento a la } \\
\text { vivienda social }\end{array}$ & $\begin{array}{l}\text { Eliminación de } \\
\text { subsidios a la } \\
\text { vivienda social }\end{array}$ & De facto & 1983 & $\begin{array}{l}\text { Segunda etapa } \\
\text { de reformas } \\
\text { neoliberales }\end{array}$ & $\begin{array}{l}\text { Constitución } \\
\text { Nacional }\end{array}$ & 1983 \\
\hline $\begin{array}{l}\text { Derecho a la } \\
\text { vivenda }\end{array}$ & $\begin{array}{l}\text { Reconocimiento } \\
\text { constitucional } \\
\text { de la vivienda } \\
\text { digna y } \\
\text { decorosa como } \\
\text { derecho }\end{array}$ & $\begin{array}{l}\text { Reforma } \\
\text { constitucional }\end{array}$ & 1983 & $\begin{array}{l}\text { Reconocimiento } \\
\text { indirecto de la } \\
\text { vivienda } \\
\text { adecuada }\end{array}$ & $\begin{array}{l}\text { Artículo } 11 \text { del } \\
\text { Pacto } \\
\text { Internacional } \\
\text { de Derechos } \\
\text { Económicos, } \\
\text { Sociales y } \\
\text { Culturales }\end{array}$ & $\begin{array}{l}\text { Adhesión en } \\
1971\end{array}$ \\
\hline $\begin{array}{l}\text { Privatización en } \\
\text { producción de } \\
\text { vivienda social }\end{array}$ & $\begin{array}{l}\text { El estado } \\
\text { materializa } \\
\text { créditos } \\
\text { hipotecarios a } \\
\text { través de } \\
\text { grandes } \\
\text { constructoras } \\
\text { (GEO, URBI, } \\
\text { ARA, etc.) }\end{array}$ & De facto & 1990 & $\begin{array}{l}\text { Consolidación } \\
\text { de modelo } \\
\text { neoliberal, } \\
\text { política } \\
\text { centrada en } \\
\text { subsidios a la } \\
\text { demanda. }\end{array}$ & De facto & 1990 \\
\hline $\begin{array}{l}\text { Producción masiva } \\
\text { de vivienda social }\end{array}$ & $\begin{array}{l}\text { Iniciativas de } \\
\text { gestión público- } \\
\text { privadas para la } \\
\text { creación de } \\
\text { nuevas } \\
\text { centralidades } \\
\text { urbanas en la } \\
\text { periferia, } \\
\text { Combinación } \\
\text { de subsidios } \\
\text { entre } \\
\text { instituciones } \\
\text { federales y } \\
\text { locales }\end{array}$ & $\begin{array}{l}\text { Reforma a Ley } \\
\text { de INFONAVIT } \\
\text { y Ley de los } \\
\text { Trabajadores al } \\
\text { Servicio del } \\
\text { Estado }\end{array}$ & 2000 & $\begin{array}{l}\text { Políticas de } \\
\text { reconstrucción } \\
\text { post } 27 \mathrm{~F} \text {. Rol } \\
\text { radical de } \\
\text { agentes } \\
\text { privados para la } \\
\text { provisión de } \\
\text { vivienda con } \\
\text { apoyo de } \\
\text { fondos estatales }\end{array}$ & De facto & 2010 \\
\hline $\begin{array}{l}\text { Subsidios a la } \\
\text { localización }\end{array}$ & $\begin{array}{l}\text { Definición de } \\
\text { Perímetros de } \\
\text { Contención } \\
\text { Urbana }\end{array}$ & $\begin{array}{l}\text { Programa de } \\
\text { Esquemas de } \\
\text { Financiamiento } \\
\text { y Subsidio } \\
\text { Federal para } \\
\text { Vivienda "Esta } \\
\text { es tu casa" }\end{array}$ & 2011 & $\begin{array}{l}\text { Subsidio } \\
\text { diferenciado a } \\
\text { la localización, } \\
\text { con apoyo para } \\
\text { la adquisición } \\
\text { de terrenos }\end{array}$ & $\begin{array}{l}\text { Programa } \\
\text { Fondo Solidario } \\
\text { de Vivienda }\end{array}$ & 2006 \\
\hline
\end{tabular}

Fuente: Elaboración propia con información de Hidalgo (2005) y García (2010). 
Tabla 2 - Iniciativas estatales de políticas de vivienda no comparables entre México y Chile.

\begin{tabular}{|c|c|c|c|}
\hline \multicolumn{4}{|l|}{ México } \\
\hline Característica & Iniciativa / medida & Instrumento Legal & $\begin{array}{l}\text { Año de } \\
\text { implementación }\end{array}$ \\
\hline $\begin{array}{l}\text { Construcción de } \\
\text { Grandes conjuntos de } \\
\text { seguridad social }\end{array}$ & $\begin{array}{l}\text { Producción de vivienda para clase media } \\
\text { burocrática }\end{array}$ & De facto & $1940-1960$ \\
\hline $\begin{array}{l}\text { Vivienda social en } \\
\text { alquiler }\end{array}$ & $\begin{array}{l}\text { Financiamiento combinado (fondos } \\
\text { federales y externos) para construcción de } \\
\text { vivienda social }\end{array}$ & De facto & Década 1960 \\
\hline $\begin{array}{l}\text { Creación de } \\
\text { Fideicomisos para } \\
\text { fomento a vivienda } \\
\text { social }\end{array}$ & $\begin{array}{l}\text { Fideicomiso de Habitaciones Populares } \\
\text { (FJHP) y Fideicomiso Fondo Nacional de } \\
\text { Habitaciones Populares (FONHAPO) }\end{array}$ & $\begin{array}{l}\text { Ley Orgánica de } \\
\text { BANOBRAS }\end{array}$ & $\begin{array}{l}1981(\mathrm{FHP}) \text { y } 1985 \\
\text { (FONHAPO) }\end{array}$ \\
\hline $\begin{array}{l}\text { Tránsito a la noción de } \\
\text { vivienda-derecho por } \\
\text { vivienda-mercancía }\end{array}$ & Privatización en la producción de vivienda & $\begin{array}{l}\text { Reformas a Ley del } \\
\text { IMSS y Ley del ISSSSTE }\end{array}$ & 1990 \\
\hline $\begin{array}{l}\text { Apertura en el } \\
\text { mercado del suelo }\end{array}$ & $\begin{array}{l}\text { Se legaliza la desafectación de tierra de } \\
\text { propiedad social a privada }\end{array}$ & $\begin{array}{l}\text { Reforma } \\
\text { constitucional }\end{array}$ & 1992 \\
\hline $\begin{array}{l}\text { Financiarización } \\
\text { privada de la vivienda } \\
\text { social }\end{array}$ & Reforma Urbana & $\begin{array}{l}\text { Nueva Ley General } \\
\text { de Asentamientos } \\
\text { Humanos }\end{array}$ & 2012 \\
\hline $\begin{array}{l}\text { Vivienda social } \\
\text { sustentable }\end{array}$ & $\begin{array}{l}\text { Incorporación de características de } \\
\text { sustentabilidad para }\end{array}$ & $\begin{array}{l}\text { Programa de } \\
\text { Esquemas de } \\
\text { Financiamiento y } \\
\text { Subsidio Federal para } \\
\text { Vivienda "Esta es tu } \\
\text { casa" }\end{array}$ & 2007 \\
\hline \multicolumn{4}{|l|}{ Chile } \\
\hline Característica & Iniciativa / medida & Instrumento Legal & $\begin{array}{l}\text { Año de } \\
\text { implementación }\end{array}$ \\
\hline $\begin{array}{l}\text { Déficit de vivienda } \\
\text { para clases } \\
\text { desfavorecidas }\end{array}$ & $\begin{array}{l}\text { Iglesia católica y empresas privadas a cargo } \\
\text { del aprovisionamiento de vivienda social }\end{array}$ & De facto & Antes de 1953 \\
\hline $\begin{array}{l}\text { Desregulación en el } \\
\text { uso de suelo }\end{array}$ & $\begin{array}{l}\text { El suelo es un bien no escaso, se diluye la } \\
\text { regulación de su uso }\end{array}$ & $\begin{array}{l}\text { Política de Desarrollo } \\
\text { Urbano }\end{array}$ & 1979 \\
\hline $\begin{array}{l}\text { Privatización de la } \\
\text { provisión de servicios, } \\
\text { descentralización de } \\
\text { política social }\end{array}$ & Segunda etapa de reformas "neoliberales" & Constitución Chilena & 1983 \\
\hline $\begin{array}{l}\text { Fin de la dictadura, } \\
\text { gobiernos de centro- } \\
\text { izquierda }\end{array}$ & $\begin{array}{l}\text { Se consolida el modelo neoliberal, la crisis } \\
\text { de la vivienda se asocia a la expansión } \\
\text { masiva de su acceso. Gasto público } \\
\text { destinado a políticas subsidiarias a la } \\
\text { demanda. Movimientos de pobladores y } \\
\text { "tomas" como solución habitacional de } \\
\text { población de menor ingreso } \\
\text { (autoconstrucción con asistencia del } \\
\text { Estado) }\end{array}$ & Constitución Chilena & 1990 \\
\hline
\end{tabular}

Fuente: Elaboración propia con información de Hidalgo (2005) y García (2010). 


\section{El origen de las políticas subsidiarias a la localización de vivienda social}

La OCDE (2013) reconoce los avances registrados a inicios del siglo XXI en Chile en el acceso a la vivienda, identificando en las políticas subsidiarias e inversión en infraestructura urbana dos factores relevantes en este proceso. En México, una política de magnitud mayor en el fomento a la vivienda de clases medias y bajas se trazó durante la década de 1990 junto a un discurso orientado a la absorción de una demanda habitacionalmente insatisfecha. El INFONAVIT, principal promotor estatal, adquirió en este periodo nuevas funciones como facilitador, cediendo el control de la producción de vivienda social a grandes consorcios inmobiliarios, acción recomendada por instituciones de alcance global (Banco Mundial, 1994; García, 2010; Puebla, 2006). Chile experimenta de igual forma una resignificación del Estado en su participación dentro de la producción inmobiliaria, intensificado con la inserción de nuevos dispositivos legales enfocados en simplificar el acceso a fuentes de financiamiento (Cattaneo, 2011).

El resultado de lo anterior en México se materializó en una expansión urbana sin precedentes, ligada a la reducción significativa de la densidad en áreas centrales, donde de 2006 a 2013, 46 de las 59 zonas metropolitanas del país edificaron el 70\% de las viviendas nuevas en las periferias, siendo el $90 \%$ de ellas de tipo unifamiliar. La falta de accesibilidad a las nuevas viviendas se sumó a lo anterior, provocando los registros más altos de vivienda desocupada de la OCDE, con el 14.2\%, una cifra aún superior a países severamente afectados por la burbuja inmobiliaria de 2009 como España, Irlanda y Portugal (OCDE, 2013).

Ante este escenario, el Gobierno mexicano planteó una serie de estrategias como la Política Urbana y de Vivienda de 2013 (EUM, 2013) y el Programa Nacional de Vivienda 2014-2018 (EUM, 2014), donde la subsidiariazación como política adquiere protagonismo bajo las figuras de Hipoteca Verde, Desarrollos Urbanos Certificados, Perímetros de Contención Urbana (PCU) y la extensión del subsidio habitacional dentro del programa NAMA (Acciones de Mitigación Nacionalmente Aceptadas, por su sigla en inglés), estas últimas formuladas en el contexto de la Convención Marco de las Naciones Unidas para el Cambio Climático. De igual manera, se vinculó esta política al Programa de Consolidación Urbana y Habitacional, destinado a la producción de un parque habitacional orientado a disminuir eventuales impactos ambientales, así como un conjunto de medidas orientadas a la contención de la expansión horizontal de las áreas urbanas del país.

\section{La noción de subsidio según la legislación en Chile y México}

La construcción de las definiciones legales del concepto subsidio, ofrecidas por las normas más adelante analizadas para ambos países, aporta una aproximación a la visión política de las soluciones habitacionales para población socioeconómicamente vulnerable. El análisis y comprensión de los glosarios incorporados a la reglamentación de los programas subsidiarios y la normativa de ellas derivada, constituyen una fuente relevante para tal propósito.

Las reglas de operación del Programa de Esquemas de Financiamiento y Subsidio Federal para Vivienda "Esta es Tu Casa", utiliza el término subsidio federal definido como el "monto del apoyo económico no recuperable que otorga el Gobierno Federal a los Beneficiarios del Programa, de acuerdo con los criterios de objetividad, equidad, transparencia, publicidad y temporalidad, para que lo apliquen en una solución habitacional" (CONAVI, 2009). Por su parte, la legislación chilena, mediante el Decreto 174 de 2005, reconoce al Subsidio Habitacional como "ayuda estatal directa, que se otorga por una sola vez al beneficiario sin cargo de restitución por parte de éste y que constituye un complemento del ahorro que necesariamente deberá tener el beneficiario, destinado a proporcionar una solución habitacional a familias que viven en condiciones de vulnerabilidad" (MINVU, 2005). El Programa Fondo Solidario de Elección de Vivienda, a pesar de carecer de un glosario de términos, se refiere a la diferenciación por localización, equiparando el concepto de subsidio con el de subvención, ambas figuras jurídicas distintas, pues mientras la primera se refiere a una ayuda estatal de carácter asistencial, el segundo concepto tiene un campo de aplicación dirigido al fomento de actividades económicas donde el Estado posee una obligación legal (Flores, 2011). Estos 
elementos son el carácter pecuniario, el objeto asistencial y el origen estatal del recurso, coincidentes con el destino de los aportes hacia una solución habitacional y en la modalidad de entrega sin restitución de los montos otorgados por parte de quienes los adjudican (GF-CDEMX, 2015a).

\section{Política de subsidios en México}

La política de subsidios a la vivienda en México siguió los pasos del modelo chileno basado en la producción masiva de vivienda social a partir de agentes inmobiliarios privados (Rolnik, 2012). Este proceso facilitó que los subsidios habitacionales sustentaran este sector económico, al facilitar el traspaso de recursos públicos a entidades privadas, mitigando riesgos inherentes a esta actividad y generando beneficios directos a los desarrolladores (Hidalgo et al., 2016).

Para el caso de México, son escasos los estudios que se acerquen al tema, por ser una política de reciente implementación. Este proceso de reformas coincide temporalmente con la desaparición de la Secretaría de la Reforma Agraria y la creación de la Secretaría de Desarrollo Agrario, Territorial y Urbano (SEDATU) y la Comisión Nacional de Vivienda (CONAVI). Trabajos como los realizados por Martínez (2017) y Rivero et al. (2018), así como el estudio sobre criterio de entorno para la vivienda social en México del Centro Mario Molina (2016) y el elaborado por la Escuela de Graduados de Diseño de la Universidad de Harvard (Forsyth et al., 2016), incorporan a su análisis la reestructuración normativa, institucional y conceptual de los parámetros locacionales para la construcción de proyectos de vivienda social.

\section{Esta es tu casa, el diseño del nuevo modelo financiarización de vivienda}

La política de subsidios durante los gobiernos de alternancia política en México (2000-2012), estuvieron enfocados en facilitar el acceso a hipotecas a partir de "mecanismos de mejora de vivienda, auto construcción, remodelación y mejora de materiales" (Correa-López, 2014, p. 19). Los subsidios federales a la vivienda fueron canalizados a las principales empresas constructoras de vivienda social (GEO, URBI, ARA, HOMEX). Durante ese período el fomento a esta producción habitacional con participación privada es considerado un importante motor parar la economía nacional (CIDOC/SHF, 2015).

De los instrumentos de financiarización diseñados para estas operaciones, destaca el denominado Esta es tu casa (CONAVI, 2007) que, desde 2007, incorpora en sus reglas de operación elementos locacionales en la provisión de subsidios. Desde 2011, el monto del subsidio se computa a partir del equipamiento, ubicación, tipología de vivienda, densidad y superficie de espacio habitable que las unidades habitacionales en oferta posean, entregándoles un puntaje según estas particularidades. Por otro lado, se consideran aspectos de competitividad y equipamiento de áreas libres, la red de transporte público y las ecotecnologías utilizadas para reducir el impacto ambiental de la vivienda (CONAVI, 2011).

El esquema del programa "Esta es tu casa", presenta relevantes similitudes con el Fondo Solidario de Elección de Vivienda en Chile de 2012 (MINVU, 2011). El FSV establece una diferenciación comunal del monto del subsidio, asignando montos menores a las comunas ubicadas en la Región Central, además de condicionar la aplicación del subsidio al emplazamiento de vivienda en áreas urbanas, dentro del territorio operacional de empresas sanitarias, con acceso a vías de comunicación local, servicios de salud, educativos, y transporte público.

Los defectos en la política de vivienda social en México, se agudizaron a partir de la administración de Vicente Fox (2000-2006) (Correa-López, 2014), instrumentada desde el INFONAVIT y el FOVISSSTE, las dos principales agencias hipotecarias paraestatales. El gobierno mexicano, en un intento por detener el crecimiento expansivo de las ciudades, agudizado sobre todo en los primeros años de la década anterior, estableció barreras regulatorias a partir de la definición de límites de crecimiento urbano (Salinas, 2016; Forsyth et al., 2016). 
El Plan Nacional de Desarrollo 2007-2012 propuso una política orientada a ampliar su volumen habitacional desarrollando mecanismos de financiamiento para al sector privado de la construcción (CFPCDEMX, 2007). Para ello emprendió modificaciones políticas a la Comisión Nacional de Vivienda, buscando promover la movilidad habitacional en la población con menores ingresos dentro del mercado laboral formal. Con la promulgación del Programa de Esquemas de Financiamiento y Subsidio Federal para Vivienda (MINVU, 2007), se pretendió generar soluciones habitacionales cofinanciadas entre instituciones crediticias y aportaciones gubernamentales, como los "Subsidios al frente", entregados de manera directa al beneficiario para la adquisición de vivienda nueva o usada, la autoconstrucción o su mejoramiento (CONAVI, 2007). Además, impuso medidas para la diversificación de los riesgos para inversionistas privados, priorizando este beneficio a familias con ahorros personales previos. Este instrumento no consideraba criterios locacionales para la entrega del subsidio, sin embargo, puede considerarse la base normativa del Programa "Esta es tu casa".

Este programa ejecutaba unos primeros criterios de localización, condicionando la entrega de subvenciones para predios dotados de servicios, aumentando en un $20 \%$ el monto del subsidio para soluciones habitacionales que cumplieran con parámetros de sustentabilidad o verticalidad, sin precisar su consistencia y características de suficiencia.

Para 2008, la modificación a las Reglas de Operación del programa de subsidios mexicano (CONAVI, 2009), presentó como principal cambio el establecimiento de montos diferenciados para el otorgamiento del subsidio dirigido a proyectos denominados Vivienda Nueva Sustentable, dejando a criterio de la CONAVI la categorización de los parámetros y la verificación de su cumplimiento. La denominación de Vivienda Nueva Sustentable permaneció únicamente para el ejercicio 2008, eliminándose al año siguiente al establecer que se privilegiarán las soluciones habitacionales que cuenten con parámetros de sustentabilidad definidos por el Comité Técnico de Evaluación, integrado por representantes de las entidades de gobierno.

Las modificaciones a las reglas de operación del programa en 2011 suponen los primeros cambios significativos al ordenamiento (CONAVI, 2011). Primero incluye a la figura de los Desarrolladores de Vivienda Social y Ejecutor Social como entidades incorporadas a los esquemas de financiamiento. Reglamenta, además, la Producción Social de Vivienda Asistida, instrumento para el asesoramiento y producción de soluciones habitacionales de carácter social con participación privada. Así mismo, establece montos diferenciados para los subsidios en función a la tipología de los proyectos habitacionales, priorizando la verticalización residencial y el financiamiento para mejoras en viviendas usadas, todas condicionantes indirectas ligadas a la localización. Por último, crea la figura de los Desarrollos Urbanos Integrales Sustentables (DUIS) como modelo de intervención urbana sujeta a objetivos de minimización de los efectos medioambientales en la producción habitacional.

Para 2012, las reglas de operación del programa de Esquemas de Financiamiento y Subsidio Federal para Vivienda "Esta es tu Casa" se reformulan de manera substancial, organizando la dotación de recursos a partir de un sistema de puntaje regido por las condiciones de localización y sustentabilidad del entorno para cada proyecto habitacional. Este mecanismo considera el valor de la residencia y delimita los montos del subsidio con acuerdo a variables de equipamiento, redensificación y competitividad. Criterios como la existencia de establecimientos educativos de nivel básico y de salud, equipamiento, áreas libres y accesibilidad, la densidad poblacional, e incorporación de ecotecnologías en los proyectos de vivienda también son asociados a estos programas.

En 2013, una nueva modificación a la normativa incorpora a la nueva Secretaría de Desarrollo Agrario Territorial y Urbano (SEDATU), mandatada como entidad pública responsable de convocar, integrar y coordinar la certificación de los proyectos de vivienda DUIS, además de la determinación del segundo contorno urbano (S3), de acuerdo con el radio de cobertura de una escuela de nivel secundaria (SEDATU, 2013). 
La Política Urbana y de Vivienda de 2013, supuso una modificación sustancial a la regulación de los subsidios a la localización en México, a partir de la elaboración de un modelo geoestadístico para la definición de los perímetros de contención urbana (PCU) para las 384 ciudades que conforman el Sistema Urbano Nacional (SUN), seleccionadas según densidad y utilizando como criterio aquellas con 15 mil o más habitantes (CONAPO, 2012). Empleado por el gobierno federal, el instrumento define los subsidios a la vivienda con la intención de identificar su mejor ubicación respecto a la proximidad con fuentes de empleo y servicios, divididas en tres categorías: U1, U2 y U3 donde la primera subdivisión se integra por áreas urbanas consolidadas, la segunda por un radio en torno a esos polígonos y la última se define por el borde envolvente a centros de trabajo y un contorno que rodea las áreas U2.

Parte de los cambios incorporados a las operaciones del programa "Esta es tu casa" está referido a la extensión de soluciones habitacionales con estándares de sustentabilidad vinculados a programas como NAMA, creados por la Convención Marco de las Naciones Unidas para el Cambio Climático, orientados a la eficiencia en el consumo de recursos. La fortaleza de esta agregación está en la extensión del subsidio dentro de los polígonos delimitados por el Programa de Consolidación Urbana y Habitacional (PROCHURA). Esta condición también se repite para predios inscritos en el Registro Nacional de Reservas Territoriales (RENARET), siempre que la solución habitacional no se localice en zonas con índices altos de vivienda abandonada. La aplicación del subsidio es prioritaria para población considerada en pobreza multidimensional según el Consejo Nacional de Evaluación de la Política de Desarrollo Social siendo relevantes las dimensiones involucradas en derechos sociales, como vivienda y servicios.

Transformaciones de relevancia sobre este sistema se instituyen para favorecer la incorporación de mecanismos de fomento a la formalidad, a partir del presupuesto fiscal. Mediante el "Programa Crezcamos Juntos" se establecieron condiciones para la obtención de hipotecas en la banca comercial, posibilitando la adquisición de viviendas ubicadas fuera de los límites PCU, cuando el valor de esta fuera inferior a 200 veces el Salario Mínimo. Este cambio orientó sus parámetros con los objetivos establecidos en la Cruzada Contra el Hambre, paquete de medidas destinadas a mitigar la pobreza extrema. La extensión del subsidio también procedió sobre los polígonos identificados por la Secretaría de Desarrollo Social (SEDESOL) como Zonas de Atención Prioritaria (ZAP), caracterizados por grados tipificados como alto y muy alto de marginación (SEDATU, 2014).

La política subsidiaria en 2016 se alinea al Programa Nacional de Vivienda 2014-2018, así como al Programa Sectorial de Desarrollo Agrario, Territorial y Urbano. Para este último se diseña el subsidio adicional vinculado a la localización de vivienda social, denominado "Programa de Consolidación de Reservas Urbanas" de 2017. Destinado a otorgar apoyos económicos para la adquisición de suelo intraurbano en proyectos desarrollo de vivienda social vertical, constituye un aporte adicional a los ofertados por SEDATU -cuyos montos responden a un sistema de puntaje- por un máximo de 50\% para proyectos ubicados en la Ciudad de México; e impone, como requisito en el último perímetro urbano (U3), la inclusión del Sistema Integral de Autobus Intraurbanos de Transito Rápido (BRT). En la instrumentación de este subsidio se privilegian proyectos urbanos en los polígonos ZAP para población con pobreza alimentaria extrema, así como en municipios donde opere el Programa Nacional para la Prevención Social de la Violencia y la Delincuencia. En el marco de este paquete de reformas, el Programa de Acceso al Financiamiento para Soluciones Habitacionales prioriza subsidios a la vivienda para población vulnerable no relacionada directamente con aspectos económicos -mujeres en situación de víctimas, personas con discapacidad y jóvenes.

\section{Los instrumentos de subsidio a la vivienda en Chile}

En 2001, el Gobierno Chileno a través del Ministerio de Vivienda y Urbanismo (MINVU), sanciona el Decreto Supremo 155, creador del Fondo Solidario de Vivienda (FSV). El objetivo de esta política está en generar soluciones habitacionales para familias de escasos recursos dentro del mercado de la vivienda 
formal, mediante un esquema de financiamiento combinado entre subsidio base, subsidios complementarios, ahorros propios y, en algunos casos, hipotecas otorgadas por la banca (MINVU, 2001).

Con la reglamentación de 2005 -Decreto Ley 174-, el FSV incorpora parámetros de diferenciación en la política subsidiaria vinculada a la localización de viviendas. Para ello, desarrolla un sistema de puntaje para la selección de sus beneficiarios considerando factores de evaluación de la vivienda y del entorno. La localización, el punto fuerte de esta evaluación, considera la conectividad directa con la red vial existente, proximidad a servicios de transporte público, además de equipamientos educacionales y de salud (MINVU, 2005).

Para 2006, el Decreto 226 modifica al FSV, creándose el Subsidio Diferenciado a la Localización (SDL) como subvención adicional para la adquisición de terrenos, condicionado a los requisitos establecidos por los factores de evaluación de localización ya descritos, incorporando requerimientos de localización en áreas urbanas reconocidas por los instrumentos de planificación territorial locales, factibilidad sanitaria, existencia de una red vial y acceso a la red de transporte público (MINVU, 2006). Para 2007, un segundo ajuste extiende este beneficio para la adquisición de viviendas existentes, así como para la habilitación de terrenos, siempre que cumplan con los factores de evaluación del entorno correspondientes (MINVU, 2007).

Luego de cinco años de funcionamiento, con el Decreto Supremo 49 de 2012, el FSV es rediseñado, denominándose Fondo Solidario de Elección de Vivienda. Esta norma considera al SDL como un instrumento de financiarización adicional al Subsidio Habitacional para la adquisición o construcción de viviendas, este último condicionado en su cuantía a la comuna donde se localice el proyecto, asignando montos menores en las comunas ubicadas dentro la Zona Central del país. Por otro lado, focaliza los alcances del instrumento a la población considerada entre el 40 y 90 por ciento más vulnerable a nivel nacional. Además, prioriza su aplicación sobre nuevos proyectos habitacionales o como complemento al pago del precio de vivienda construida dentro del área operacional de una empresa sanitaria, con acceso a vías de comunicación local, servicios de salud, educativos y a la red de transporte público. En el ámbito rural, se materializa con el funcionamiento del subsidio a la factibilidad para áreas no urbanas, promoviéndose para proyectos ubicados a no más de mil metros de distancia sobre el límite urbano más cercano y a menos de 100 metros de una vialidad de servicio o de rango superior existente (MINVU, 2011).

En 2015 el decreto número 105 modifica las reglas de aplicación del Programa Fondo Solidario de Elección de Vivienda reconociendo nuevamente al SDL como complementario (MINVU, 2015). Adicionalmente incluye como requisitos de localización, la existencia de equipamiento comercial, deportivo o cultural, así como de área verde cercana a la ubicación del terreno o el emplazamiento de la vivienda a adquirir. La última modificación que registra este programa tiene lugar con la promulgación del Decreto 22 de 2017, que distingue montos superiores para el subsidio de factibilidad cuando se trate de proyectos ubicados en comunas con baja densidad poblacional como las localizadas en las regiones de Aysén y Magallanes (MINVU, 2017).

\section{Conclusiones}

El mercado de la vivienda se ha integrado a los circuitos financieros a partir de la participación de empresas multinacionales en este proceso, trayendo consecuencias considerables sobre los propietarios individuales de la tierra (Rolnik, 2012). En México, esto se acentúa en los propietarios colectivos, pues es en los núcleos ejidales donde se materializa la afectación en la continuidad de sus actividades económicas con la enajenación de actividades productivas. Rolnik (2012) se refiere específicamente a los casos de Chile y México, donde se produce un efecto centrífugo de los valores del suelo en sus principales ciudades. Este proceso fue apalancado con el repliegue del Estado en esta tarea, mediante el establecimiento de políticas para el subsidio a la vivienda de la población de menores ingresos, acentuando el protagonismo de la iniciativa privada. 
La relación propuesta en el manuscrito destaca la transformación acontecida en México durante los gobiernos de la alternancia, productores de estrategias clave de atención al déficit habitacional y las demandas de vivienda. Durante este período se estima la necesidad de duplicar el parque habitacional existente para los siguientes treinta años, cantidad que ascendía a 23 millones de unidades (CONAVI, 2011). La estrategia decantó en el modelo subsidiario de contención urbana, iniciado en 2015, utilizado como mitigación ante la expansión urbana de las últimas décadas. Para estas acciones, la institucionalidad subsidiaria es crucial tanto en Chile como en México, pues fomenta la producción de vivienda desde el INFONAVIT y FOVISSSTE en México y SERVIU en Chile, además de orientar territorialmente la gestión de las hipotecas (García, 2010).

La integración de los mercados de la vivienda dentro de los circuitos generales de las finanzas significa que los propietarios individuales están compitiendo por mayores aptitudes de localización frente a empresas multinacionales, generando consecuencias previsibles. El citado efecto centrífugo de la apreciación de la tierra en áreas metropolitanas a nivel global establece nuevas formas de discriminación espacial, basadas en estatus económico o clase social, características observables con facilidad en ciudades de ambos países, donde la promoción de vivienda depende del cruce subsidio-hipoteca-ahorro.

Ambos casos exponen políticas de subsidios a la vivienda como mecanismos desatendidos de planificación territorial. De ahí que la generación de nichos de renta y acumulación a lo largo de las periferias urbanas en beneficio de los agentes inmobiliarios tienda a ser una constante (Hidalgo et al., 2017). Para México, la definición de áreas de crecimiento urbano considera a la localización de servicios y centros de generación de empleos como ejes, dejando una serie de interrogantes sin respuesta: ¿Son compatibles los empleos ofertados por las unidades económicas con las características de la población localizada en sus inmediaciones?, o, dicho de otra manera, ¿tienen estas unidades espaciales la capacidad para satisfacer las necesidades de empleo de quienes habitan en sus inmediaciones? Finalmente, ante un escenario líquido de expansión de la propiedad habitacional, ¿cómo operarán el reconocimiento de áreas susceptibles de ser urbanizadas en el futuro próximo?

Al contrastar el andamiaje normativo e institucional que ha condicionado la localización para la dotación de recursos públicos en el abatimiento del déficit de vivienda en la región, se evidencian diferencias sustantivas que tienen sus orígenes en la visión del derecho a la vivienda que existe en Chile y México. En cambio, fue posible identificar grandes coincidencias en ambas políticas, que queda de manifiesto en los instrumentos procedimentales y operacionales practicados en estos casos emblemáticos latinoamericanos. Con este análisis es posible identificar que estas coincidencias no obedecen a una emulación de pautas de gobierno, su ejecución en los países esgrimidos resulta de una reacción casi simultánea hacia la desregulación de los mercados de suelo urbano, para dar paso a un esquema de expansión que en términos espaciales no ha tenido precedentes, lo que plantea desafíos para la gobernabilidad de las metrópolis en el futuro.

\section{Bibliografía}

Banco Mundial. (1994). Vivienda. Un entorno propicio para el mercado habitacional. Washington. Recuperado 20 de noviembre de 2020, de http://documentos.bancomundial.org/curated/es/878771468343734154/Vivienda-un-entornopropicio-para-el-mercado-habitacional

Castillo-Fernández, S. (2018). La vivienda popular en Chile urbano (1880-1930). Un estado de la cuestión interdisciplinario. Historia (Santiago), 51(1), 227-251. https://doi.org/10.4067/s0717-71942018000100227.

Cattaneo, R. (2011). Los fondos de inversión inmobiliaria y la producción privada de vivienda en Santiago de Chile: ¿Un nuevo paso hacia la financiarización de la ciudad? EURE. Revista Latinoamericana de estudios Urbano Regionales, 37(112), 5-22. https://dx.doi.org/10.4067/S0250-71612011000300001 
Centro Mario Molina. (2016). Criterios de Entorno para la Vivienda Social en México. México. Recuperado 20 de noviembre de 2020, de http://centromariomolina.org/ciudades-sustentables/criterios-de-entorno-para-la-vivienda-social-en-mexicofase-ii-2016/

Centro de Investigación y Documentación de la Casa-Sociedad Hipotecaria Federal, CIDOC/SHF. (2015). Estado Actual de la Vivienda en México 2015. México. Recuperado 20 de noviembre de 2020, de https://www.gob.mx/cms/uploads/attachment/file/147034/EAVM_2015_N.pdf

Consejo Nacional de Población, CONAPO. (2012). Catálogo Sistema Urbano Nacional. México. Recuperado 20 de noviembre de 2020, de http://conapo.gob.mx/work/models/CONAPO/Resource/1539/1/images/PartesIaV.pdf

Comisión Nacional de Vivienda, CONAVI. (2007). ACUERDO de la Junta de Gobierno de la Comisión Nacional de Vivienda número JG-3-180107-041 por el que se formulan las Reglas de Operación del Programa de Esquemas de Financiamiento y Subsidio Federal para Vivienda. Recuperado 20 de noviembre de 2020, de http://www.dof.gob.mx/nota_to_doc.php?codnota=4962623.

Centro de Estudios de las Finanzas Públicas-Honorable Cámara de Diputados de los Estados Unidos Mexicanos, CFPCDEMX. (2007). Plan Nacional de Desarrollo, 2007-2012. Recuperado 20 de noviembre de 2020, dehttps://www.cefp.gob.mx/intr/edocumentos/pdf/cefp/cefp0962007.pdf

Comisión Nacional de Vivienda, CONAVI. (2009). ACUERDO de la Junta de Gobierno de la Comisión Nacional de Vivienda número JG-11-150509-121 por el que se modifican las Reglas de Operación del Programa de Esquemas de Financiamiento y Subsidio Federal para Vivienda Esta es tu casa. Recuperado 20 de noviembre de 2020, de http://dof.gob.mx/nota_detalle.php?codigo=5105421\&fecha=07/08/200914

Comisión Nacional de Vivienda, CONAVI. (2011). ACUERDO de la Junta de Gobierno por el que se modifican las Reglas de Operación del Programa de Esquemas de Financiamiento y Subsidio Federal para Vivienda Esta es tu casa, publicadas el 7 de agosto de 2009. Recuperado 20 de noviembre de 2020, de

http://www.dof.gob.mx/nota_detalle.php?codigo=5177681\&fecha=11/02/2011

Correa-López, G. (2014). Construcción y acceso a la vivienda en México; 2000-2012. Intersticios Sociales, 1(7), 1-31. Recuperado 20 de noviembre de 2020, de http://www.scielo.org.mx/pdf/ins/n7/n7a5.pdf.

De Mattos, C. (1999). Santiago de Chile, globalización y expansión metropolitana: lo que existía sigue existiendo. Revista EURE - Revista de Estudios Urbano Regionales, 25(76). Recuperado 20 de noviembre de 2020, de http://www.eure.cl/index.php/eure/article/view/1217.

Diario Oficial de los Estados Unidos Mexicanos (1976). Ley General de Asentamientos Humanos. Recuperado 20 de noviembre de 2020, de http://dof.gob.mx/nota_detalle.php?codigo=4845406\&fecha=26/05/1976

Flores, C. (2011). Concepto y naturaleza de la subvención en el Derecho chileno: El caso de la concesión de obra pública. Revista de Derecho de la Pontificia Universidad Católica de Valparaíso, (XXXVII), 329-367.

Forsyth, A., Brennan, C., Escobedo, N., \& Scott, M. (2016). Revitalizando Ciudades: Mejorando viviendas y barrios desde la cuadra a la metrópolis, enfatiza ejemplos internacionales y mexicanos e identifica políticas, programas y estrategias de planeación para implementar las políticas de vivienda mexicanas del 2012. Cambridge, MA: Harvard University Graduate School of Design. Recuperado 20 de noviembre de 2020, de https://dash.harvard.edu/handle/1/29312107

García, B. (2010). Vivienda social en México (1940-1999): actores públicos, económicos y sociales. Cuadernos de Vivienda y Urbanismo, 3(5), 34-49.

Girón, A., \& Chapoy, A. (2009). Financiarización y titulización: un momento Minsky. Economía UNAM, 6(16), 44-56. Recuperado 20 de noviembre de 2020, de http://www.scielo.org.mx/pdf/eunam/v6n16/v6n16a3.pdf

Estados Unidos Mexicanos, EUM (2013). Política Urbana y de Vivienda. Subsecretaría de Desarrollo Urbano y Vivienda. Secretaría de Desarrollo Agrario, Territorial y Urbano. Recuperado el 20 de noviembre de 2020, de https://www.senado.gob.mx/comisiones/vivienda/foros/politica_nacional.pdf

Estados Unidos Mexicanos, EUM (2014). Programa Nacional de Vivienda 2014-2018. Subsecretaría de Desarrollo Urbano y Vivienda. Secretaría de Desarrollo Agrario, Territorial y Urbano. Recuperado el 20 de noviembre de 2020, de https://www.dof.gob.mx/nota_detalle.php?codigo=5342865\&fecha=30/04/2014

Estados Unidos Mexicanos, EUM (2017). Constitución Política de los Estados Unidos Mexicanos. Recuperado 20 de noviembre de 2020, de http://www.diputados.gob.mx/LeyesBiblio/pdf/1_080520.pdf 
Gobierno_Federal-Honorable Cámara de Diputados de los Estados Unidos Mexicanos, GF-CDEMX. (2015a). Ley Federal de Presupuesto y Responsabilidad Hacendaria (2015). México: Diario Oficial de la Federación. Recuperado 20 de noviembre de 2020, de http://www.diputados.gob.mx/LeyesBiblio/ref/lfprh.htm

Gobierno_Federal-Honorable Cámara de Diputados de los Estados Unidos Mexicanos, GF-CDEMX. (2015b). Reglamento Orgánico del Fondo de la Vivienda del ISSSTE. México: Diario Oficial de la Federación. Recuperado el 20 de noviembre de 2020, de http://www.diputados.gob.mx/LeyesBiblio/regla/n256.pdf

Gobierno_Federal-Honorable Cámara de Diputados de los Estados Unidos Mexicanos, GF-CDEMX (1972). Ley del Instituto del Fondo Nacional de la Vivienda para los Trabajadores. Recuperado 20 de noviembre de 2020, de http://www.diputados.gob.mx/LeyesBiblio/pdf/86_010519.pdf

Hidalgo, R. (2005). La vivienda social en Chile y la construcción del espacio urbano en Santiago. Santiago de Chile: Serie GEOlibros-DIBAM.

Hidalgo, R., Alvarado, V., \& Santana, D. (2017). La espacialidad neoliberal de la producción de vivienda social en las áreas metropolitanas de Valparaíso y Santiago (1990-2014): ¿hacia la construcción idelógica de un rostro humano? Cadernos Metrópole, 19(39), 513-535. https://doi.org/10.1590/2236-9996.2017-3907.

Hidalgo, R., Arenas, F., \& Santana, D. (2016). ¿Utópolis o distópolis? Producción inmobiliaria y metropolización en el litoral central de Chile (1992-2012). Revista EURE - Revista Latinoamericana de estudios Urbano Regionales, 42(126), 27-54. http://dx.doi.org/10.4067/S0250-71612016000200002.

Higuera, A., \& Rubio, M. (2011). La vivienda de interés social: sostenibilidad, reglamentos inter- nacionales y su relación en México. Quivera, 13(2), 193-208.

Imilan, W., Olivera, P., \& Beswick, J. (2016). Acceso a la vivienda en tiempo neoliberales: Un análisis comparativo de los efectos e impactos de la neoliberalización de las ciudades de Santiago, México y Londres. Revista INVI, 31(88), 163-190. http://dx.doi.org/10.4067/S0718-83582016000300006.

Isunza, G. (2010). Política de vivienda y movilidad residencial en la Ciudad de México. Estudios Demográficos y Urbanos, 25(2), 277-316.

Jessop, B. (1999). Crisis del Estado de Bienestar: hacia una nueva teoría del Estado y sus consecuencias sociales (Primera Ed). Bogotá, Colombia: Siglo del Hombre Editores, Universidad Nacional de Colombia.

Lentini, M. (2005). Política habitacional de Argentina y Chile durante los noventa. Un estudio de política comparada. Revista INVI, 20(55), 139-153. Recuperado 20 de noviembre de 2020, de http://revistainvi.uchile.cl/index.php/INVI/article/view/322/886.

Martínez, A. N. (2017). Vivienda en abandono. Análisis socio espacial de la vivienda abandonada en México. Territorios en Formación, 12, 41-54. https://dx.doi.org/10.20868/tf.2017.12.3647.

Ministerio de Vivienda y Urbanismo, Chile, MINVU (2001). Decreto No. 155, reglamenta otorgamiento de subsidios habitacionales modalidad fondo concursable para proyectos habitacionales solidarios. Recuperado 20 de noviembre de 2020, de https://www.bcn.cl/leychile/navegar?idNorma=189318

Ministerio de Vivienda y Urbanismo, Chile, MINVU (2005). Decreto No. 174, reglamenta programa Fondo Solidario de Vivienda. Recuperado 20 de noviembre de 2020, de

https://www.bcn.cl/leychile/navegar?idNorma=247299\&org=nxc2\%3Fid_c\%3D1028

Ministerio de Vivienda y Urbanismo, Chile, MINVU (2006). Decreto No. 226, modifica decreto nำ174 (V. y U.), de 2005.

Recuperado 20 de noviembre de 2020, de https://www.bcn.cl/leychile/navegar?idNorma=255417

Ministerio de Vivienda y Urbanismo, Chile, MINVU (2007). Decreto No. 126, Modifica el decreto No. 174 de 2005, Reglamento del Programa Fondo Solidario de Vivienda. Recuperado 20 de noviembre de 2020, de https://www.leychile.cl/Navegar?idNorma=263959

Ministerio de Vivienda y Urbanismo, MINVU (2011). Decreto No. 49 Aprueba reglamento del Programa Fondo Solidario de Elección de Vivienda. Recuperado 20 de noviembre de 2020, de https://www.leychile.cl/Navegar?idNorma=1039424

Ministerio de Vivienda y Urbanismo, MINVU (2014). Hacia una nueva política urbana para Chile. Antecedentes históricos. Santiago de Chile: MINVU. 
Ministerio de Vivienda y Urbanismo, MINVU (2015). Decreto No. 105, modifica decreto no 49, de 2011, que reglamenta el Programa Fondo Solidario de Elección de Vivienda. Recuperado 20 de noviembre de 2020, de https://www.bcn.cl/leychile/navegar?idNorma=1075618

Ministerio de Vivienda y Urbanismo, MINVU (2017). Decreto No. 22, modifica decreto supremo ${ }^{\circ}{ }^{1}$, de 2011, reglamento del Sistema Integrado de Subsidio Habitacional; decreto supremo ${ }^{\circ} 49$, de 2011, reglamento del Programa Fondo Solidario de Elección de Vivienda; decreto supremo ${ }^{\circ}$ 52, de 2013, reglamento del programa de Subsidio de Arriendo de Vivienda; decreto supremo $n^{\circ}$ 105, de 2014, que modifica decreto supremo $n^{\circ} 49$, del Ministerio de Vivienda y Urbanismo, de 2011; decreto supremo $\mathrm{n}^{\circ}$ 10, de 2015, que reglamenta el Programa de Habitabilidad Rural; decreto supremo ${ }^{\circ}$ 19, de 2016, reglamento Programa de Integración Social y Territorial, todos del Ministerio de Vivienda y Urbanismo. Recuperado 20 de noviembre de 2020, de https://www.bcn.cl/leychile/navegar?idNorma=1104401

Moncayo, E. (2002). Nuevos enfoques teóricos, evolución de las políticas regionales e impacto territorial de la globalización. Instituto Latinoamericano y del Caribe de Planificación Económica y Social (Primera Ed). Santiago de Chile: Instituto Latinoamericano y del Caribe de Planificación Económica y Social - ILPES. Recuperado 20 de noviembre de 2020, de https://repositorio.cepal.org/bitstream/handle/11362/7277/1/S0212982_es.pdf.

Naciones Unidas (1976). Pacto Internacional de Derechos Económicos, Sociales y Culturales. Recuperado 20 de noviembre de 2020, de https://www.ohchr.org/sp/professionalinterest/pages/cescr.aspx

Naranjo, C., \& Purcell, J. (2010). La Dimensión Cualitativa en el Sistema de Postulación al Fondo Solidario de Vivienda I. Psicoperspectivas, 9(1), 181-202. http://doi.org/10.5027/psicoperspectivas-Vol9-Issue1-fulltext-100

OCDE. (2013). The Chilean urban system and its challenges. En OCDE Urban Policy Reviews (Primera Ed, p. 31-76). Santiago de Chile: OCDE Publishing. Recuperado 20 de noviembre de 2020, de https://www.oecd-

ilibrary.org/docserver/9789264191808-

en.pdf?expires=1562356171\&id=id\&accname=oid039122\&checksum=CAB8B2D17DC1396066173FE3BE5448DD

Ossul-Vermehren, I. (2018). Lo político de hacer hogar: una mirada de género a la vivienda autoconstruida. Revista INVI, 33(93), 9-51. https://doi.org/10.4067/S0718-83582018000200009.

Puebla, C. (2006). El Instituto del Fondo Nacional de la Vivienda para los Trabajadores (Infonavit). En Schteingart, M. \& Coulomb, R. (Coords). Entre el Estado y el mercado: la vivienda en el México de hoy, México (Primera Ed, p. 193-238). México: Editorial Porrúa.

Rivero, M., Moreno, E., \& Velázquez, M. (2018). Los perímetros de contención urbana: Nuevo marco decisional. En Hoyos, G., Serrano, S., \& Mora, M. (Eds.), Ciudad, Género, Cultura y Educación en las Regiones (Primera Ed, p. 56-81). México: Universidad Nacional Autónoma de México y Asociación Mexicana para el Desarrollo Regional. Recuperado 20 de noviembre de 2020, de http://ru.iiec.unam.mx/3920/

Rodríguez, A., \& Sugranyes, A. (2004). El problema de vivienda de los con techo. Revista EURE - Revista Latinoamericana de estudios Urbano Regionales, (Santiago), 30(91), 53-65. https://doi.org/10.4067/S0250-71612004009100004.

Rojas, M., Bran, N., \& Rincón, C. (2013). Modelos de financiación de vivienda. Casos: México, Chile y Colombia. Revista Ingenierías Universidad de Medellín, 12(22), 97-108. Recuperado 20 de noviembre de 2020, de http://www.scielo.org.co/pdf/rium/v12n22/v12n22a09.pdf.

Rolnik, R. (2012). Informe de la Relatora Especial sobra una vivienda adecuada como elemento integrante del derecho a un nivel de vida adecuado. Washington. Recuperado 20 de noviembre de 2020, de http://observatoridesc.org/sites/default/files/informe_relatora_onu_oct2012.pdf.

Salinas, L. (2016). Política de vivienda social y gestión metropolitana en la expansión de la periferia de la ZMCM. Cuadernos Geográficos, Universidad de Granada, 55(2), 217-237. Recuperado 20 de noviembre de 2020, de https://revistaseug.ugr.es/index.php/cuadgeo/article/view/3888/5148

Schteingart, M., \& García, B. (2006). Nuevas políticas de vivienda en México. Nuevas relaciones entre sector público y privado y retos para el futuro. En Borjas, A., \& Bucio, M. (Eds.), La vivienda en México: construyendo análisis y propuestas (Primera Ed, p. 39-50). México: Centro de Estudios Sociales y de Opinión Pública.

Schteingart, M., \& Patiño, L. (2006). El marco legislativo, programático e institucional de los programas habitacionales. En Coulomb, R., \& Schteingart, M. (Eds.), Entre el Estado y el mercado: la vivienda en el México de hoy (Primera Ed, p. 153-192). México: Universidad Autónoma Metropolitana Azcapotzalco - Miguel Ángel Porrúa. 
Secretaría de Desarrollo Agrario, Territorial y Urbano - SEDATU. (2013). Primer Informe de Labores 2012-2013. Recuperado por 5 de mayo de 2019, de http://www.sedatu.gob.mx/sraweb/datastore/home_store/index/INFORME_LABORES 2013.pdf.

Secretaría de Desarrollo Agrario, Territorial y Urbano, SEDATU. (2014). Reglas de Operación del Programa Nacional de Vivienda 2014. México: Diario Oficial de la Federación. Recuperado 20 de noviembre de 2020, de http://www.cmic.org.mx/comisiones/Sectoriales/vivienda/2016/REGLAS DE OPERACION/PROGRAMA Nacional de Vivienda 2014.pdf.

Urrutia, J. P. (2018). Competencia política y presupuesto de vivienda en años electorales en Chile entre 1990 y 2015. Revista INVI, 33(94), 189-208. https://doi.org/10.4067/S0718-83582018000300189.

Yopo Díaz, M., Rivera Aburto, S., \& Peters Riveros, G. (2012). Individuación y políticas sociales en Chile: Sobre la experiencia de nuevas propietarias en la comuna de Lo Espejo. Polis (Santiago), 11(32), 241-266. https://doi.org/10.4067/S071865682012000200013.

Editor: Paulo Nascimento Neto

Recibido: 10 Jul. 2019

Aprobado:I 17 Sep. 2020 


\section{Errata}

En el artículo "La organización del mercado del suelo y los subsidios a la localización de vivienda como soluciones desde la política neoliberal en Chile y México", con el número de DOI https://doi.org/10.1590/2175-3369.013.e20190170, publicado en urbe. Revista

Brasileira de Gestão Urbana, vol. 13, e20190170, en la página 1,

donde lees:

"Luis Salinas Arreourtua"

leer:

"Luis Salinas Arreortua" 